\title{
Характеристика суточных сумм атмосферных осадков на Западном Кавказе
}

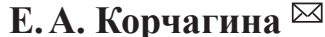 \\ ФГБНУ «Федеральный научный центр \\ «Кабардино-Балкарский научный иентр Российской академии наук», \\ Центр географических исследований, Российская Федераиия \\ (360002, г. Нальчик, ул. Балкарова, 2)
}

\begin{abstract}
Аннотация: Практика отслеживания колебаний климата основана на анализе рядов наблюдаемых на метеостанциях значений приземной температуры воздуха и сумм атмосферных осадков. Исследования режима осадков на Западном Кавказе показывают, что при ощутимых климатических изменениях расчеты не выявляют статистически достоверной динамики в среднегодовых суммах осадков.

Цель настоящей работы - исследовать современные изменения характеристик суточных сумм атмосферных осадков на Западном Кавказе.

Материалы и методы. Основой для расчетов являются наблюдения на метеостанциях, представленные в специализированных массивах ВНИИГМИ-МЦД. Метод исследования - математико-статистическое моделирование.

Результаты и обсуждение. Установлено, что, несмотря на существенные локальные различия в режиме осадков, рост числа дней с осадками различной интенсивности, увеличение средних и/или максимальных значений их суточной интенсивности в октябре являются общими тенденциями на исследуемой территории. В большинстве пунктов выявлены тенденции увеличения количества дней с осадками различной интенсивности и средних суточных и максимальных сумм в марте. Статистически достоверные тенденции к снижению различных характеристик суточной интенсивности на Западном Кавказе обнаружены зимой, в апреле и в августе.

Заключение. Несмотря на локальные особенности режима осадков можно отметить некоторые общие тенденции. Во-первых, повсеместно обнаружен рост значений различных характеристик режима осадков в октябре, увеличение числа дней с осадками различной интенсивности, рост средних и/или максимальных значений их суточной интенсивности. А поскольку в регионе наводнения в октябре явление довольно частое, то обнаруженные статистически достоверные тенденции свидетельствуют, что вероятность наступления зависимых от интенсивности и частоты осадков опасных природных явлений в этом месяце не снижается. Во-вторых, увеличение количества дней с осадками и суточных характеристик в марте (исключение составляет метеостанция Шаджатмаз). В-третьих, снижение суточной интенсивности осадков зимой, в апреле и в августе. На фоне отсутствия значимых изменений в годовых суммах осадков установлено их перераспределение внутри года и выявлены статистически достоверные линейные тренды суточных характеристик осадков, способные повлиять на режим стока рек в регионе и формирование на них опасных гидрологических явлений.
\end{abstract}

Ключевые слова: региональное изменение климата, число дней с осадками, динамика временного ряда, математико-статистическое моделирование.

Для цитирования: Корчагина Е.А. Характеристика суточных сумм атмосферных осадков на Западном Кавказе // Вестник Воронежского государственного университета. Серия: География. Геоэкология, 2021, № 3, с. 25-32. DOI: https://doi.org/10.17308/geo.2021.3/3597

\section{ВВЕДЕНИЕ}

Наиболее частые наводнения на Западном Кавказе и прилегающих равнинах связаны с интенсивными атмосферными осадками, особенно когда они совпадают с периодом весенне-летне- го половодья. Примером могут служить дожди большой интенсивности, вызвавшие в июле 2012 года разрушительное наводнение в населенных пунктах Краснодарского края [7]. Не меньше от наводнений и опасных паводков страдают Ады-

(C) Корчагина Е.А., 2021

\ Елена Александровна Корчагина, e-mail: helena.a.k@mail.ru

(c) (i) Контент доступен под лицензией Creative Commons Attribution 4.0 License.

Вестник ВГУ, Серия: География. Геоэкология, 2021, № 3, 25-32 
гея, Ставропольский край, Карачаево-Черкесская Республика. В горных районах Западного Кавказа, основной речной системой которого является бассейн реки Кубани, интенсивность и продолжительность атмосферных осадков играют значительную роль и для процессов образования снежных лавин, селей, оползней. Нельзя не учитывать этот фактор и при анализе горной территории с целью оценки ее природной опасности $[6,9]$.

В исследованиях динамики регионального и глобального климата отмечается, что для годовых сумм атмосферных осадков тренды статистически недостоверны и не отражают происходящих изменений $[10,11,14]$. Не являются исключением и районы Западного Кавказа с прилегающими к ним территориями. Изучение режима осадков в этом регионе показывает, что при ощутимых климатических изменениях статистически достоверной динамики среднегодовых значений сумм осадков не выявлено. Динамика сезонных или месячных сумм осадков демонстрирует более детальную картину. Но в целом проблематично определить характер изменения данного климатического показателя в регионах.

Изменение режима осадков происходит на фоне повышения средних сезонных и годовых значений температуры воздуха $[3,5]$.

От количества осадков и величины температуры воздуха зависят такие показатели, как влажность почвы, режим таяния снега, влияющие на различные фазы стока рек. Авторы работы [8] считают сочетание количества выпадающих осадков, влажности почвы и таяния снега ведущими факторами образования наводнений. Во многих регионах Европы, в том числе и на Европейской части России, обнаружены положительные тренды дождей большой интенсивности $[11,12]$. В отдельных районах Западного Кавказа также отмечен рост суточной интенсивности осадков на фоне слабой изменчивости годовых сумм осадков и роста температуры воздуха [14]. В этих условиях анализ изменения суточных характеристик выпадающих осадков, как и анализ динамики количества дней с осадками различной интенсивности, является обоснованным.

При расчете относительных характеристик осадков за базовое значение принимают параметр, осредненный либо за 1961-1990 годы, либо за весь период исследований [1]. Наиболее принятые точки отсчета изменения климатических параметров - 1936 год [1], середина 20-ого века (1959 [4] или 1961), а современный этап
(1971 [2], 1976). Заканчиваются рассматриваемые ряды 2000-2018 годами.

Понятие дня с сильными осадками определяется авторами индивидуально в зависимости от региона исследования. Например, в работе [1] рассматривают день с сильными осадками как суточную сумму осадков, превышающую средний многолетний суточный максимум втрое. В Росгидромете обращают внимание на значения, превышающие стандартное отклонение Гауссова распределения более чем в 3 раза.

Несмотря на различие в определениях понятия «дня с сильными осадками», полученные различными исследователями метеопараметры показывают, что их результаты находятся в принципиальном согласии.

Количество дней с осадками, их средняя суточная и максимальная суточная интенсивность важные показатели режима атмосферных осадков на Западном Кавказе.

Цель нашего исследования - выявить тренды суточных характеристик режима осадков, а также количества дней с осадками более установленного порога в районах Западного Кавказа и в его предгорьях.

\section{МАТЕРИАЛЫ И МЕТОДЫ}

Всемирная метеорологическая организация (BMO), кроме общего количества осадков, к основным климатологическим параметрам относит число дней с осадками более одного мм, границы квинтилей их распределения (мм) среднее число суток в месяце с осадками более 5, 10, 50, 100, 150 мм, максимальное значение суточных сумм (мм) [13].

Для расчета климатических норм используют месячные значения, осредненные за выбранный период. Для сумм атмосферных осадков эти значения, рассчитанные путем обработки измерений, проведенных в течение месяца, следующие: 1) средние суточные суммы осадков; 2) максимальное или минимальное из суточных значений; 3) число дней с суточной суммой осадков выше или ниже заданного порога.

Общепринятая практика отслеживания климатических изменений - это соотнесение их с некоторыми базовыми значениями. Базовые значения рассчитываются за период не менее 30 лет. Согласно рекомендациям ВMO, в настоящей статье относительные изменения характеристик суточных осадков будем сравнивать с рассчитанными нормами 1961-1990 годов.

Динамика указанных параметров исследована по материалам, представленным в специализиро- 
ванных массивах ВНИИГМИ МЦД'. Метеорологические станции, показатели которых доступны в базе данных, распределены по территории Западного Кавказа неравномерно. Так, Шаджатмаз (434ㄴ с.ш., 4240' в.д., 2070 м над ур. моря), Клу-

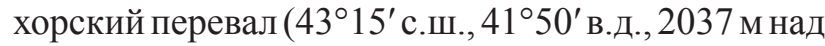

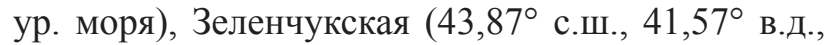
928 м над ур. моря) находятся в восточной горной части бассейна Кубани на северном склоне

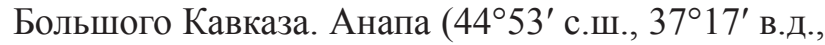
30 м над ур. моря) и Красная поляна $\left(43^{\circ} 41^{\prime}\right.$ с.ш., $40^{\circ} 12^{\prime}$ в.д., 564 м над ур. моря, южный склон Большого Кавказа) расположены в западной части исследуемой территории. Суточные данные метеостанций, в результате обработки которых построены временные ряды средних, расчетных и экстремальных параметров атмосферных осадков, доступны с 1960 по 2018 годы ${ }^{1}$. Показательны еще два периода. Первый, 1966-2018 годы, когда кардинальных изменений в методах и режиме проведения измерений на сети метеостанций не было и данные можно считать однородными. Второй период, так называемый период интенсивного потепления, 1976-2018 годы, время наибольших скоростей подъема приземной температуры воздуха. Расчеты нами проведены для двух периодов.

Для каждой метеостанции рассчитано количество дней с осадками $N^{j}$ и $N_{i}^{j}-$ количество дней с осадками не менее і мм, где $i \in(1,5,10,15,20,25,30,40,50) \mathrm{мм}, j-$ месяц или сезон.

Рассчитана средняя $\mathrm{R}$, мм, и максимальная $\mathrm{R}_{\max }$, мм, суточная интенсивность:

$$
R=\frac{I^{j}}{N^{j}}
$$

где $I^{j}$ - сумма выпавших осадков за ј-ый месяц, мм.

$$
R_{\max }=\max R^{j}
$$

где $\mathrm{R}^{j}$ - множество сумм суточных осадков j-ого месяца.

Большую популярность в исследованиях изменений климата приобрели методы математико-статистического моделирования. В настоящей статье мы использовали линейную модель трендов временных рядов климатических параметров в следующем виде:

$$
y=b^{j} \cdot t+a
$$

где $y$-средний, экстремальный или расчетный параметр атмосферных осадков, $t$ - время (год или декада), $j$ - месяц или сезон, за который осреднен параметр, $b^{j}$ - скорость изменения уровней временного ряда параметра в $j$-ом месяце или сезоне, $a$-свободный член уравнения, точка пересечения уравнения регрессии с осью $y$.

Для определения значимости полученных оценок трендов проведены статистические тесты. Гипотезы формулировались следующим образом. Утверждение о том, что отличие оценки коэффициента уравнения (3) от 0 случайно, принято за нулевую гипотезу. Принятие этой гипотезы в нашем случае означает отсутствие направленных изменений:

$$
H_{0}: b^{j}=0
$$

Альтернативная гипотеза утверждает, что отличие оценки коэффициента линейной регрессии в уравнении (1) от 0 не случайно.

$$
H_{1}: b^{j} \neq 0
$$

Подтверждение альтернативной гипотезы свидетельствует о наличии устойчивой тенденции в ряду динамики характеристик режима осадков.

\section{РЕЗУЛЬТАТЫ И ОБСУЖДЕНИЕ}

Результаты расчетов оценок трендов средней и максимальной за месяц суточной интенсивности за периоды 1960-2018, 1966-2018 и 1976-2018 годов подвергнуты анализу только те значения коэффициентов линейной регрессии месяцев и календарных сезонов, для которых тесты подтвердили статистическую достоверность вычисленных трендов.

Так, наименьшее количество параметров, изменения которых достоверны на 0,05 уровне значимости, отмечены на водоразделе Терека и Кубани, метеостанции Шаджатмаз. Отмечено статистически достоверное снижение средней суточной интенсивности осадков в декабре, апреле и августе. Остальные тренды незначимы.

В высокогорных районах восточной части бассейна реки Кубани по данным метеостанции Клухорский перевал выявлено снижение числа дней с осадками в декабре, увеличение числа дней с осадками в марте. Усиление средней суточной интенсивности осадков в сентябре, октябре. Увеличение суточных максимумов приходится на октябрь, осень, год.

Наиболее длинный набор параметров, претерпевших статистически достоверные измене-

\footnotetext{
${ }^{1}$ Булыгина О.Н., Разуваев В.Н., Коршунова Н.Н., Швец Н. В. Описание массива данных суточной температуры воздуха и количества осадков на метеорологических станциях России и бывшего ССCP (TTTR). - Свидетельство о государственной регистрации базы данных № 2014620942. URL: http://meteo.ru/data/162-temperature-precipitation\#описание-массива-данных (дата обращения: 07.08.2019)
} 
ния в восточной части бассейна Кубани, выявлен по данным метеостанции Зеленчукская. Статистически незначимы тренды только у двух параметров: общее количество дней с садками $\mathrm{N}^{\mathrm{j}}$ и количество дней с осадками более 1 мм $\mathrm{N}_{1}{ }^{\mathrm{j}}$. Статистически значимы следующие тренды: 1) увеличение дней с осадками более 5 мм в марте и январе; 2) количество дней с осадками более 10 мм увеличилось в марте, июне, октябре, снизилось в августе за 1976-2018 годы; $3)$ количество дней с осадками более 15 мм значимо снизилось в апреле, увеличилось в октябре за 1960-2018 годы; 4) количество дней с осадками более 20 мм снизилось в январе и за календарный зимний сезон, увеличилось в июне, сентябре и за календарный осенний сезон в целом за все исследуемые периоды 1960-2018 годы, 1966-2018 годы, 1976-2018 годы; 5) количество дней с осадками более 30 мм увеличилось в июне, снизилось в мае 1966-2018 годы; 6) количество дней с осадками более 40 мм увеличилось в июне, снизилось в августе за 1976-2018 годы.

При этом сами значения скорости изменения параметра невелики: от - 0,03 суток/10 лет для

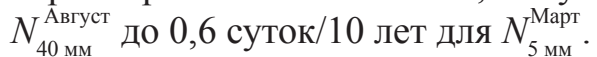

На рисунке 1 представлено годовое распределение числа дней с осадками за базовый период 1961-1990 годов по данным метеостанции Зеленчукская. Если выразить скорости изменения в процентах к климатической норме, то для для $N_{40 \text { мм }}^{\text {Авгст }}$ она составит $11 \% / 10$ лет, а для $N_{5 \text { мм }}^{\text {Март }} 30 \% / 10$ лет.

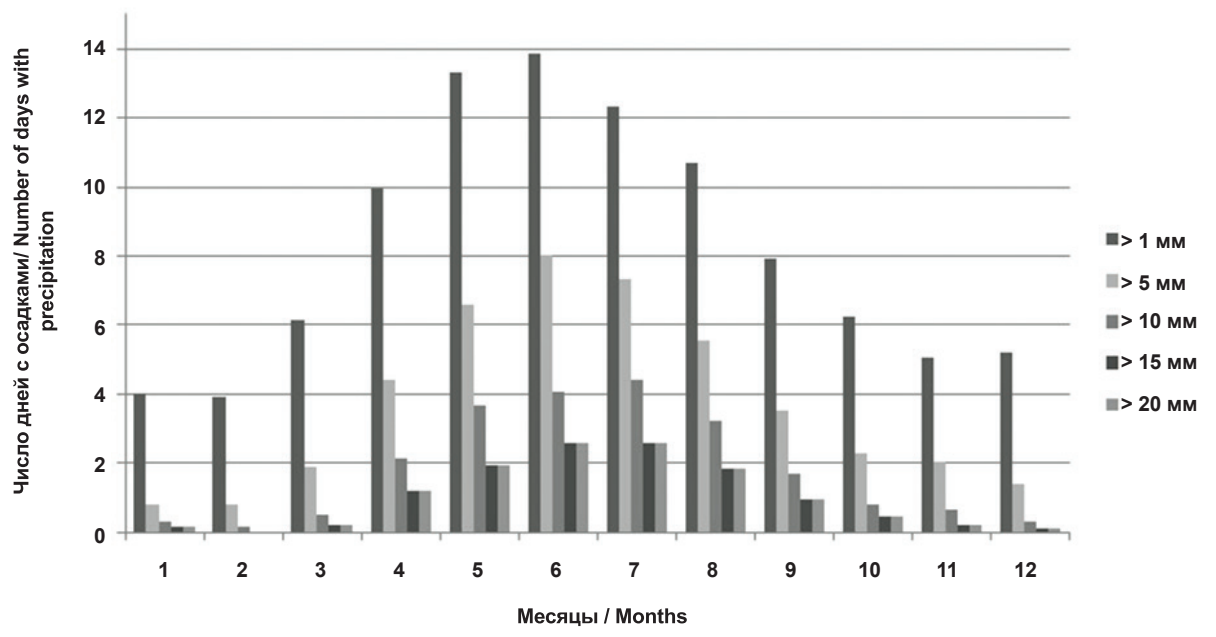

Рuc. 1. Годовое распределение числа дней с осадками за базовый период 1961-1990 годов, метеостанция Зеленчукская

[Fig. 1. The annual distribution of days with precipitation for the base period 1961-1990, Zelenchukskaya weather station]

В западной части бассейна реки Кубани по данным метеостанции Анапа установлено статистически значимое изменение следующих параметров: 1) увеличение числа дней с осадками в марте и в целом весной 1960-2018 годов и 19762018, а за период 1966-2018 еще и за год; 2) увеличение числа дней с осадками более 1 мм в марте 1960-2018 годов и 1966-2018; 3) увеличение числа дней с осадками более 5 мм в марте и весной 1960-2018 годов и 1966-2018; 4) увеличение числа дней с осадками более 10 мм в январе 1960-2018 годов и 1966-2018 и в октябре в 1976-2018 годов; 5) увеличение числа дней с осадками больше 15 и 20 мм в октябре, больше 30 мм в сентябре 1976-2018 годов; 6) снижение числа дней с осадками более 40 мм в апреле 1960-2018 годов и за 19662018 годы; 7) увеличение числа дней с осадками более 50 мм в октябре 1960-2018 годов и осенью 1976-2018 годы; 8) увеличение средней суточной интенсивности осадков в октябре со скоростью 1,4 мм/сут./10 лет в период 1976-2018 лет; 9) снижение максимальной суточной интенсивности в августе -3,3 мм/сут./10 лет за период 1960-2018 годы; увеличении максимальной суточной интенсивности в октябре 5,9 мм/сут./10 лет и осенью 2,6 мм/сут./10 лет за период 1976-2018 годов.

Метеостанция Красная поляна расположена в западной части южного склона Западного Кавказа. По ее данным выявлены следующие тенденции, статистически значимые на уровне 0,05 : 1) увеличение числа дней с осадками в марте со скоростью 0,8 сут./10 лет (1966-2018 годы); снижение в апреле -1,2 сут./10 лет (1976-2018 годы); 2) увеличение числа дней с осадками более 1 мм 
в марте 1960-2018 годы, $b_{1 \text { мм }}^{\text {март }}=0,6$ сут. $/ 10$ лет; в 1976-2018 годах скорость роста увеличилась до 1,1 сут./10 лет; снижение числа дней с осадками в апреле - 1,2 сут./10 лет за 1976-2018 годы; 3 ) увеличение числа дней с осадками более 5 мм в марте, $b_{5 \text { мм }}^{\text {Март }}=0,7$ сут./10 лет за 1966-2018 годы и $b_{1 \text { мм }}^{\text {Мap }}=1,2$ сут. $/ 10$ лет за 1976-2018 годы; снижение в августе - 1,2 сут./10 лет за 1976-2018 годы; 4) количество дней с осадками более 10 мм увеличилось в марте за все исследуемые периоды, снизилось в августе за периоды 1960-2018 годов и 1966-2018 годов со скоростью - 0,4 сут./10 лет; $5)$ количество дней с осадками более 15 мм уве- личилось в апреле со скоростью 0,33 сут./10 лет и в октябре со скоростью 0,4 сут./10 лет за период 1960-2018; снизилось за август - 0,4 сут./10 лет в длинные периоды; 6) число дней с осадками более 50 мм увеличилось в апреле 0,1 сут. $/ 10$ лет за 1960-2018 годы и 1966-2018 годы; а снизилось в январе - 0,3 сут./10 лет и зимой - 0,1 сут./10 лет за 1976-2018 годы.

Годовой ход количества дней с осадками различной интенсивности, рассчитанный за базовый период 1961-1990 годов по данным метеостанции Красная поляна, представлен на рисунке 2 .

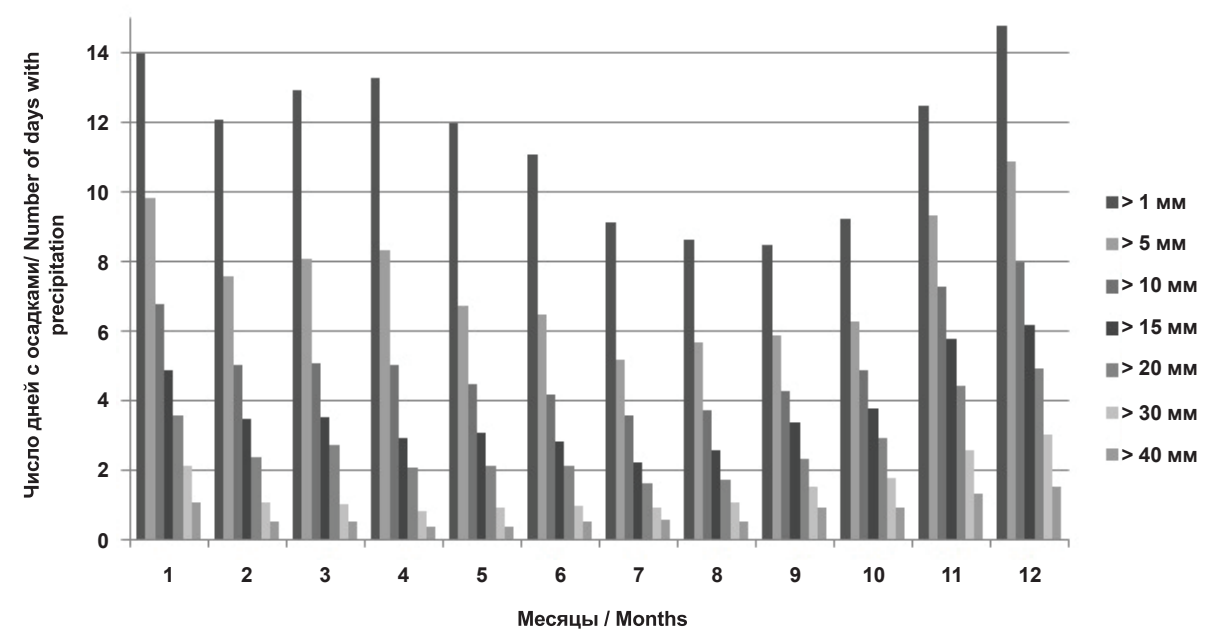

Рис. 2. Годовое распределение числа дней с осадками за базовый период 1961-1990 годов, метеостанция Красная поляна

[Fig. 2. Annual distribution of days with precipitation for the base period 1961-1990, Krasnaya Polyana weather station]

Сопоставление изменений числа дней с осадками различной интенсивности с динамикой изменения суточных характеристик осадков дает основание полагать, что в районе метеостанции Зеленчукская основную роль в росте средних суточных и максимальных суточных сумм осадков в июне играет рост числа дней с осадками от 20 мм до 50 мм. Рост суточных характеристик в октябре обусловлен ростом числа дней с осадками от 10 до 20 мм. Снижение средних суточных и максимальных сумм в августе обеспечено снижением количества дней с осадками от 10 до 15 мм и падением числа дней с осадками более 40 мм.

В районе метеостанции Анапы достоверный рост суточных характеристик осадков в октябре в 1976-2018 годах обеспечен ростом числа дней с осадками от 10 до 30 мм. К увеличению $R_{\max }^{\text {Осен }}$ кроме октябрьских значений имеет отношение рост числа дней с осадками более 30 мм в сентябре.
Абсолютные значения рассчитанных трендов невелики: от 0,01 сут./10лет ( $N_{50 \text { мм, }}^{\text {Апель }} 1960-2018$ годы, Красная поляна) до 1,5 сут./10 лет $\left(N_{1 \text { мм9 }}^{\text {Март }}\right.$ 1976-2018 годы, Клухорский перевал). Но в процентном соотношении к значениям, рассчитанным за базовый период (см. рисунки 1-2), они дают прирост (убыль) от 30 до 90 \% за весь период исследования (43-59 лет).

Из анализа полученных данных можно установить следующий характер изменений климата на Западном Кавказе. В верховьях притоков реки Кубани вблизи водораздела (метеостанция Шаджатмаз) статистически значимых изменений сезонных сумм атмосферных осадков не выявлено. Обнаруженные тренды имеют тенденцию к снижению, но статистически незначимы. Тренды числа дней с осадками разной интенсивности имеют такие же характеристики, и только снижение средней суточной интенсивности в апреле, августе и декабре неслучайно. 
В верховьях реки Кубани в высокогорной зоне (метеостанция Клухорский перевал) достоверно установлено увеличение количества дней с осадками в марте. При этом среднесуточная интенсивность увеличилась в сентябре, октябре и осенью за период 1960-2018 годов. Максимальные суточные осадки усилились в октябре и осенью.

В низкогорной зоне (метеостанция Зеленчукская) обнаружено увеличение количества дней с осадками более 5 мм в марте, более 15 мм в октябре, рост числа дней с осадками более 20 мм в июне и за осенний календарный сезон. Также установлено статистически достоверное увеличение числа дней с осадками более 30 мм и более 40 мм в июне и снижение числа дней с осадками более 50 мм в августе.

Таким образом, из общих тенденций в восточной части бассейна можно отметить увеличение дней с осадками и суточных характеристик осадков в марте, а также повышение средней и максимальной суточной интенсивности осадков осенью, особенно в сентябре и октябре.

Установлены тенденции по метеостанции 3еленчукская к увеличению осадков более 20, 30 и 40 мм и суточных характеристик в их снижении для дней с осадками более 50 мм в августе. В высокогорных районах подобные явления не обнаружены.

Для западной части исследуемой территории можно определить следующие общие черты - это увеличение числа дней с осадками более 5 мм в марте, рост суточной интенсивности в октябре за 19762018 годы. Снижение числа дней в апреле более 40 мм на равнине (метеостанция Анапа), числа дней с осадками более 1 мм в низкогорье (метеостанция Красная поляна). Обнаружено снижение параметров осадков в августе: суточных максимумов за 1960-2018 годы в равнинной части, дней с осадками более 5 мм в низкогорной. Из различий можно отметить снижение средней и максимальной суточной интенсивности летом и отсутствие изменения режима осадков осенью на южном склоне Западного Кавказа (метеостанция Красная поляна).

\section{ЗАКЛЮЧЕНИЕ}

Несмотря на локальные особенности режима осадков можно отметить некоторые общие тенденции. Во-первых, повсеместно обнаружен рост значений различных характеристик режима осадков в октябре, увеличение числа дней с осадками различной интенсивности, рост средних и/или максимальных значений их суточной интенсивности. А поскольку в регионе наводнения в октябре явление довольно частое, то обнаруженные статистически достоверные тенденции свидетельствуют, что вероятность наступления зависимых от интенсивности и частоты осадков опасных природных явлений в этом месяце не снижается.

Во-вторых, увеличение количества дней с осадками и суточных характеристик в марте (исключение составляет метеостанция Шаджатмаз).

В-третьих, снижение суточной интенсивности осадков зимой, в апреле и в августе.

На фоне отсутствия значимых изменений в годовых суммах осадков установлено их перераспределение внутри года и выявлены статистически достоверные линейные тренды суточных характеристик осадков, способные повлиять на режим стока рек в регионе и формирование на них опасных гидрологических явлений.

\section{СПИСОК ЛИТЕРАТУРЫ}

1. Богданова Э.Г., Гаврилова С. Ю., Ильин Б.М. Изменение числа дней с сильными осадками на территории России за период 1936-2000 гг. // Метеорология и гидрология, 2010, № 5, с. 75-81.

2. Данова Т.Е., Касаджик Т. Л. Оценка современной изменчивости повторяемости и количества осадков статистическими методами // Научные ведомости БелГУ. Серия: Естественные науки, 2013, № 7 (160), с. 155-162.

3. Корчагина Е. А. Изменчивость температуры воздуха в предгорных районах Северо-Кавказского федерального округа // Материалы V Международной научно-практической конференции: «Фундаментальные и прикладные аспекты геологии, геофизики и геоэкологии с использованием современных информационных технологий», 2019, с. 204-211.

4. Корчагина Е.А. Исследование устойчивости тенденций элементов климата в высокогорье Карачаево-Черкесии с 1959 по 2017 гг. // Вестник КРАУНЦ. Физико-математические науки, 2018, №3 (23), с. 106-115.

5. Корчагина Е.А. Исследование температурного режима в горных районах Кабардино-Балкарии и Карачаево-Черкесии в 1951-2015 гг. // Устойчивое развитие горных территорий, 2019, т. 11, № 4 (42), с. 449-458.

6. Кюль Е. В., Борисова Н.А. Геолого-геоморфологический анализ горной территории при оценке природной опасности (на примере Кабардино-балкарской республики) // Вестник Воронежского государственного университета. Серия: География. Геоэкология, 2017, № 2, с. 59-67.

7. Паспорт гидрометеорологической безопасности Краснодарского края. Обнинск, 2017. 117 с.

8. Blöschl $\mathrm{G}$ et al. Changing climate both increases and decreases European river floods // Nature, 2019, Sep; 573(7772), pp. 108-111.

9. Kyul E.V., Ezaov A.K., Kalov R.O., Nazranov Kh.M., Ashurbekova T.N. Landschaftliche analyse des territoriums bei der auswertung der naturhaften gefahr (an dem beispiel der Kabardino-Balkarischen re- 
publik, Zentral Kaukasus) // Dilemas contemporáneos: Educación, Política y Valores, 2019, vol. 6, no. S3, pp. 108.

10. Myhre, G., Alterskjær, K., Stjern, C.W. et al. Frequency of extreme precipitation increases extensively with event rareness under global warming. Sci Rep 9, 16063 (2019), pp. 132-137.

11. Nilsen I. B., Fleig A. K., Tallaksen L. M. \& Hisdal H. Recent trends in monthly temperature and precipitation patterns in Europe // Hydrology in a Changing World: Environmental and Human Dimensions Proceedings of FRIEND-Water 2014, Montpellier, France, October 2014 (IAHS Publ. 363, 2014), pp. 132-137.

12. Trenberth K. Changes in Precipitation with Climate Change. Climate Change Research // Climate Research, 47, pp. 123-138.
13. WMO Guidelines on the Calculation of Climate Normals. WMO, 2017.

14. Ye H. et al. Increasing daily precipitation intensity associated with warmer air temperatures over Northern Eurasia / (H. Ye, ... +6 ..., B.L. Gamelin) // J. Clim. no. 29 (2016), pp. 623-636.

Конфликт интересов: Автор декларирует отсутствие явных и потенциальных конфликтов интересов, связанных с публикацией настоящей статьи.

Поступила в редакцию 09.11.2020

Принята к публикацчии 03.09.2021

UDC 551.5+551.3

ISSN 1609-0683

DOI: https://doi.org/10.17308/geo.2021.3/3597

\title{
Characteristics of Daily Sums of Atmospheric Precipitation in the Western Caucasus
}

\author{
E.A. Korchagina $\bowtie$ \\ "Federal Scientific Centre "Kabardino-Balkar Scientific Centre of the Russian Academy of Sciences" \\ Centre of geographical researches, Russian Federation \\ (2, Balkarov St., Nalchik, 360002)
}

\begin{abstract}
The practice of tracking climate fluctuations is based on the analysis of series of values of surface temperature and precipitation observed at meteorological stations. Studies of the precipitation regime in the Western Caucasus show that calculations do not reveal statistically reliable dynamics in the mean annual precipitation totals in the presence of perceptible climatic changes.

The purpose of this work is to investigate current changes in the characteristics of daily precipitation totals in the Western Caucasus.

Materials and methods. The basis for the calculations are observations at weather stations provided in specialised arrays of the VNIIGMI-MDC. The research method is mathematical-statistical modelling.

Results and discussion. It has been found that, despite significant local differences in precipitation regime, an increase in the number of days with precipitation of different intensity, an increase in average and/or maximum values of their daily intensity in October are the general trends in the study area. In most locations, trends of an increase in the number of days with precipitation of different intensities and the average daily and maximum daily totals in March have been identified. Statistically significant downward trends in various daily intensity characteristics in the West Caucasus were found in winter, April and August.

Conclusion. Despite the local peculiarities of the precipitation regime, some general trends can be noted. Firstly, an increase in the values of various characteristics of the precipitation regime in October, an increase in the number of days with precipitation of various intensities, an increase in the average and/or maximum values of their daily intensity have been found across the board. And since in the region flooding in October is a fairly frequent phenomenon, the statistically reliable trends found indicate that the probability of occurrence of hazardous natural phenomena depending on the intensity and frequency of precipitation in this month does not decrease. Secondly, an increase in the number of days with precipitation and daily characteristics in March (with the exception of Shajatmaz weather
\end{abstract}

(C) Korchagina E.A., 2021

$\square$ Elena A. Korchagina, e-mail: helena.a.k@mail.ru

(c) (i) The content is available under Creative Commons Attribution 4.0 License.

Вестник ВГУ, Серия: География. Геоэкология, 2021, № 3, 25-32 


\section{E.A. Korchagina}

station). Thirdly, a decrease in the daily intensity of precipitation in winter, April and August. Against the background of no significant changes in annual precipitation totals, their redistribution within the year was established and statistically reliable linear trends in daily precipitation characteristics, which can affect the river flow regime in the region and the formation of dangerous hydrological phenomena on them, were revealed.

Key words: regional climate change, the number of days with precipitation, the dynamics of the time series, mathematical and statistical modeling.

For citation: Korchagina E.A. Characteristics of Daily Sums of Atmospheric Precipitation in the Western Caucasus. Vestnik Voronezskogo gosudarstvennogo universiteta. Seria: Geografia. Geoekologia, 2021, no. 3, pp. 25-32. (In Russ.) DOI: https://doi.org/10.17308/geo.2021.3/3597

\section{REFERENCES}

1. Bogdanova E.G., Gavrilova S. Yu., Il'in B.M. Izmenenie chisla dney s sil'nymi osadkami na territorii Rossii za period 1936-2000 gg. [Change in the number of days with heavy rainfall in Russia over the period 1936-2000] // Meteorologiya i gidrologiya, 2010, no. 5, pp.75-81. (In Russ)

2. Danova T.E., Kasadzhik T.L. Otsenka sovremennoy izmenchivosti povtoryaemosti i kolichestva osadkov statisticheskimi metodami [Assessment of current variability of repeatability and rainfall by statistical methods]. Nauchnye vedomosti BelGU. Seriya: Estestvennye nauki, 2013, no. 7(160), pp. 155-162. (In Russ)

3. Korchagina E.A. Izmenchivost' temperatury vozdukha $\mathrm{V}$ predgornykh rayonakh Severo-Kavkazskogo federal'nogo okruga [Air temperature variability in the foothills of the North Caucasus Federal district]. Materialy V Mezhdunarodnoy nauchno-prakticheskoy konferentsii: «Fundamental'nye i prikladnye aspekty geologii, geofiziki i geoekologii s ispol'zovaniem sovremennykh informatsionnykh tekhnologiy», 2019, pp. 204-211. (In Russ)

4. Korchagina E.A. Issledovanie ustoychivosti tendentsiy elementov klimata v vysokogor'e Karachaevo-Cherkesii s 1959 po 2017 gg. [The research on stability of tendencies of climate elements in the highlands of Karachay-Cherkessia from 1959 to 2017]. Vestnik KRAUNC. Fiziko-matematicheskie nauki, 2018, no. 3(23), pp. 106-115. (In Russ)

5. Korchagina E.A. Issledovanie temperaturnogo rezhima $\mathrm{v}$ gornykh rayonakh Kabardino-Balkarii i Karachaevo-Cherkesii v 1951-2015 gg. [The investigation on temperature regime in the highlands of the Kabardino-Balkarien and Karachay-Cherkes republic from 1951 to 2015]. Sustainable development of mountain territories, 2019, vol. 11, no. 4(42), pp. 449-458. (In Russ).

6. Kyul' E. V., Borisova N.A. Geologo-geomorfologicheskiy analiz gornoy territorii pri otsenke prirodnoy opasnosti (na primere Kabardino-balkarskoy respubliki) [Geological and geomorphological analysis of the mountainous area when assessing natural hazard (for example, the Kabardino-Balkarian Republic)]. Vestnik Voronezh-

Корчагина Елена Александровна

кандидат физико-математических наук, старший научный сотрудник, Центр географических исследований Кабардино-Балкарского научного центра РАН, г. Нальчик, Российская Федерация, ORCID: 0000-0001-93681666, e-mail: helena.a.k@mail.ru skogo gosudarstvennogo universiteta. Seria: Geografia. Geoekologia, 2017, no. 2, pp. 59-67. (In Russ)

7. Pasport gidrometeorologicheskoy bezopasnosti Krasnodarskogo kraya [Passport of hydrometeorological safety of the Krasnodar Territory]. Obninsk, 2017. 117 p. (In Russ)

8. Blöschl $\mathrm{G}$ et al. Changing climate both increases and decreases European river floods. Nature, 2019, Sep; 573(7772), pp. 108-111.

9. Kyul E. V., Ezaov A. K., Kalov R. O., Nazranov Kh. M., Ashurbekova T.N. Landschaftliche analyse des territoriums bei der auswertung der naturhaften gefahr (an dem beispiel der Kabardino-Balkarischen republik, Zentral Kaukasus). Dilemas contemporáneos: Educación, Política y Valores, 2019, vol. 6, no. S3, pp. 108.

10. Myhre, G., Alterskjær, K., Stjern, C.W. et al. Frequency of extreme precipitation increases extensively with event rareness under global warming. Sci Rep 9, 16063 (2019), pp.132-137.

11. Nilsen I. B., Fleig A. K., Tallaksen L. M. \& Hisdal $\mathrm{H}$. Recent trends in monthly temperature and precipitation patterns in Europe. Hydrology in a Changing World: Environmental and Human Dimensions Proceedings of FRIEND-Water 2014, Montpellier, France, October 2014 (IAHS Publ. 363, 2014), pp.132-137.

12. Trenberth K. Changes in Precipitation with Climate Change. Climate Change Research. Climate Research, 47, pp. 123-138.

13. WMO Guidelines on the Calculation of Climate Normals. WMO, 2017.

14. Ye H. et al. Increasing daily precipitation intensity associated with warmer air temperatures over Northern Eurasia / (H. Ye, ... +6 .., B.L. Gamelin). J. Clim. no. 29 (2016), pp. 623-636.

Conflict of interests: The author declares no information of obvious and potential conflicts of interestrelated to the publication of this article.

Received: 09.11.2020 Accepted: 03.09.2021

Elena A. Korchagina

Cand. Sci. (Phys. \& Math.), Senior Researcher, Centre for Geographical Research, Kabardino-Balkar Science Centre, Russian Academy of Sciences, Nalchik, Russian Federation, ORCID: 0000-0001-9368-1666,e-mail: helena.a.k@ mail.ru 